\title{
Opacité rétrocardiaque
}

\section{Retrocardiac opacity}

\section{P. Ray}

Reçu le 21 novembre 2011 ; accepté le 9 janvier 2012

(C) SFMU et Springer-Verlag France 2012

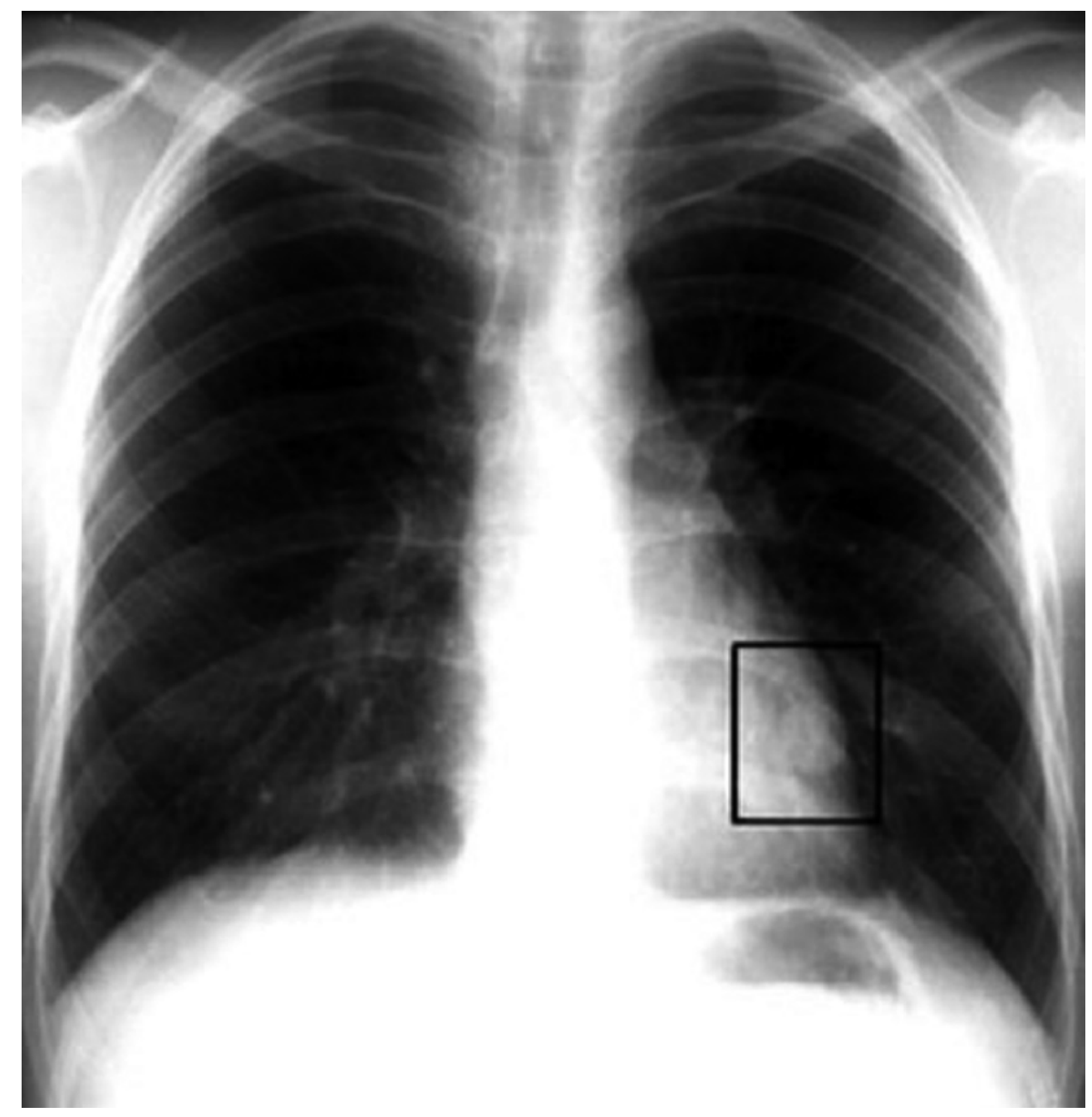

Fig. 1 Opacité rétrocardique

P. Ray $(\bowtie)$

Service d'accueil des urgences,

Groupe hospitalier Tenon-Saint Antoine,

4, rue de la Chine, F-75020 Paris,

Université Pierre et Marie Curie-Paris 6, France

e-mail : patrick.ray@tnn.aphp.fr
Cette radiographie thoracique de face (Fig. 1) mettant en évidence une opacité rétrocardiaque gauche révélatrice d'une tumeur permet d'insister sur l'importance de l'observation du parenchyme pulmonaire derrière le cœur, où de nombreuses opacités passent inaperçues à la première lecture. 